\title{
Jogo imagem e interação Uma prática educativa inclusiva
}

\section{Image and interaction}

A game for an inclusive education practice

\author{
Juego imagem e interação \\ Una práctica educativa inclusiva
}

\author{
EVANEYDE DOS SANTOS SOUZA* \\ Instituto Federal de Sergipe, Aracaju- SE, Brasil.
}

RODRIGO BOZI FERRETE**

Instituto Federal de Sergipe, Aracaju- SE, Brasil.

\begin{abstract}
RESUMO: O artigo analisa a educação inclusiva, tomando como referência a prática educativa, que neste caso teve como foco a aplicação de um jogo intitulado Imagem e Interação, com o objetivo de perceber se ele reunia características capazes de proporcionar um ambiente inclusivo na sala de aula. A pesquisa, de cunho qualitativo, adotou como metodologia o estudo de caso com um aluno diagnosticado com Transtorno do Espectro Autista (TEA). Os resultados mostram que a inclusão educacional perpassa por práticas em que o conhecimento é construído por interações no contexto social e recursos pedagógicos que auxiliem na mediação da aprendizagem.
\end{abstract}

Palavras-chave: Inclusão educacional. Interação. Jogo.

ABSTRACT: This article analyzes Inclusive Education, taking teaching practices as reference, which, in this case, has the application of a

* Graduada em Letras pela Universidade Federal da Bahia e Serviço Social pela Universidade Norte do Paraná. É Mestra em Educação pelo Instituto Federal de Sergipe e especialista em Psicopedagogia Clínica e Institucional e em Transtorno do Espectro Autista. Atua como servidora pública do corpo técnico administrativo na Universidade Federal de Sergipe. E-mail:<evaneydesouza@yahoo.com.br>.

** É licenciado em Matemática pela Universidade do Estado do Pará, Mestre em Educação pela Universidade Federal do Rio Grande do Norte e Doutor em Educação pela Universidade Federal de Sergipe. Atualmente é Professor do Instituto Federal de Sergipe e líder do Grupo de Pesquisa em Inovação Tecnológica (GPIT). E-mail:<rbferrete@gmail.com>. 
game named Image and Interaction as main focus, with the objective of understanding wether it gathers characteristics capable of providing an inclusive environment inside classrooms. The research, of qualitative nature, adopted the case-study of a student diagnosed with Autistic Spectrum Disorder (ASD) as methodology. The results show that Inclusive Education pervades through practices in which knowledge is built by interaction on a social context; and on pedagogical resources that assist on learning mediations.

Keywords: Incusive Education. Interaction. Game.

RESUMEN: El artículo analiza la educación inclusiva tomando como referencia la práctica educativa, que, en este caso, se centró en la aplicación de un juego titulado Imagem e Interação, con el objetivo de percibir si el juego reúne características capaces de proporcionar un entorno inclusivo en la clase. La investigación, de naturaleza cualitativa, adoptó como metodología el estudio de caso con un estudiante diagnosticado con el Trastorno del Espectro Autista (TEA). Los resultados muestran que la inclusión educativa se desarrolla a través de prácticas en las que el conocimiento se construye mediante interacciones en el contexto social y recursos pedagógicos que ayudan en la mediación del aprendizaje.

Palabras clave: Inclusión educativa. Interacción. Juego.

\section{Introdução}

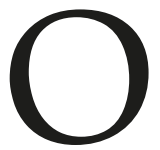

s estudos e discussões acerca da educação inclusiva não é algo novo, principalmente em relação às normas garantidoras ao acesso dos alunos em situação de inclusão no ensino regular. No entanto, destaca-se agora a necessidade de discutir a efetividade da inclusão no interior das escolas. O Brasil tem experimentado um número crescente de alunos nesta situação matriculados na rede regular de ensino. Segundo o Ministério da Educação (2019), de 2017 para 2018, registrou-se o crescimento de $11 \%$, com a maioria de alunos nas escolas públicas.

Esta realidade provocou outro olhar sobre a inclusão. Na verdade, instigou-nos a pensar a inclusão enquanto atitude e participação dos diferentes atores sociais, sobretudo no meio escolar. Dentre as atitudes, a percepção da inclusão na sala de aula através dos métodos e práticas que auxiliam a aprendizagem dos mais diferentes alunos. 
O interesse desta pesquisa não foi trazer as normas legais que legitimam o direito da educação para pessoas com deficiências, nem fazer um estudo exaustivo sobre tipos de deficiências ou, ainda, tratar da inclusão de forma generalista. Mas, sim, a partir de um caso específico - que foi um aluno com Transtorno do Espectro Autista (TEA), do curso técnico em agropecuária do ensino médio integrado do Instituto Federal de Sergipe (IFS) - discutir a sua aprendizagem através do jogo Imagem e Interação, o qual foi baseado principalmente na teoria histórico-cultural de Vygotsky e que teve por cerne a aprendizagem a partir das interações, das mediações, da socialização, do significado e sentido das palavras, e também por instrumentos que auxiliem na mediação do conhecimento e, consequentemente, no desenvolvimento intelectual.

Buscando situar este estudo na grande área da inclusão e mais especificamente da inclusão educacional de alunos com TEA no ensino médio e ensino médio integrado, foi realizada uma revisão de teses e dissertações junto ao portal de periódicos da Coordenação de Aperfeiçoamento de Pessoal de Nível Superior (Capes) e na Biblioteca Digital Brasileira de Teses e Dissertações (BDTD). A pesquisa obedeceu aos seguintes critérios: combinação das palavras-chave TEA, ensino médio e educação profissional, entre os anos de 2008 a 2019.

Foram encontradas cinco pesquisas, das quais duas tinham um caráter mais teórico e três convergiam para propostas de ensino a este perfil de aluno. Estas se aproximaram mais do presente estudo no que concerne à prática educativa, sobretudo a pesquisa de Rodrigues (2014), que visava a elaboração de propostas de educação musical a pessoas com TEA.

O TEA é estudado por diferentes correntes teóricas e distintas abordagens metodológicas se debruçam sobre o assunto. No entanto, algo é pacífico nas diferentes teorias em relação às características básicas das pessoas com TEA: "anormalidades qualitativas e quantitativas que, embora muito abrangentes, afetam de forma mais evidente as áreas da interação social, da comunicação e do comportamento" (SCHWARTZMAN, 2011, p. 37).

Portanto, é um transtorno global do desenvolvimento que tem como principal característica alterações de linguagem. E no caso em estudo não é diferente: a comunicação assertiva e a interação são justamente as áreas em que o aluno apresenta maior dificuldade.

O reconhecimento dessas características não deve servir como impedimento ou acomodação para o desenvolvimento do aluno com TEA. Pelo contrário, onde está a dificuldade de comunicação e interação é que devem surgir ações didático-pedagógicas mobilizadoras e focadas no desenvolvimento, e não nas limitações.

Desta maneira, o jogo entra em resposta às necessidades do aluno no intuito de contribuir para a sua aprendizagem, focando no aspecto social desta, ao tempo que se analisa o potencial inclusivo da prática educativa. E como perceber se a prática é inclusiva ou não? Na verdade, o recurso do jogo, como qualquer outro recurso, só se torna inclusivo pela 
intenção de promover princípios inclusivos. E, sem dúvida, a sala de aula é o ambiente propício para tal promoção. "Muito podemos fazer no interior das escolas [...] processo por processo, sem querer imediatamente resultados, tomando como ponto de partida a discussão da aprendizagem dos alunos"' (HOFFMANN, 2018, p. 43).

A sala de aula permite a convergência de metodologias e práticas educativas com objetivo nos conteúdos, nas necessidades e motivações dos alunos e com o próprio ideal educacional do professor e de toda escola. Neste processo são geradas oportunidades educacionais e as diferenças são ressignificadas.

Ojogo, ao mesmo tempo que está ligado ao prazer e distração, permite também um ambiente socializador e é um forte aliado à aprendizagem. Quando trazemos os jogos para a temática da inclusão percebemos alguns pontos e valores importantes, a saber, a aceitação das diferenças; a aprendizagem cooperativa; a oportunidade de participação; as trocas sociais; o desenvolvimento não somente cognitivo, mas também afetivo e relacional.

Ressalte-se que apesar do estudo ter por base um adolescente com TEA e o jogo ter sido pensado nas suas necessidades, a ação ou a prática não foi isolada ou excludente. Em outras palavras, o jogo foi desenvolvido em observação do contexto social, da realidade da turma. Desta forma, a análise do jogo enquanto prática educativa inclusiva se deu justamente no envolvimento e participação dos alunos em sala de aula e como o conteúdo do jogo foi desenvolvido entre os participantes.

Tanto na elaboração do jogo como na estruturação deste artigo, utilizamos teóricos que alicerçam a discussão da aprendizagem a partir de práticas educativas direcionadas ao reconhecimento das trocas sociais como propulsoras do desenvolvimento, tendo Vygotsky $(2008,2007)$ como maior referência. Além dele, autores como Hoffmann (2018) e Vial (2015) trouxeram a importância de se pensar o processo de educação a partir da mediação e dos elementos sociais e culturais. Ainda contribuíram para o estudo autores que observam a inclusão educacional enquanto ação educativa possível e processual, como Freitas (2013); Santos e Ferreira (2017); Mattos e Souza (2017) e Silva (2014).

\section{Metodologia}

A pesquisa se inseriu na abordagem qualitativa pelo interesse nas experiências e interações motivadas em um contexto natural. Além disso, todo o processo de pesquisa dialogou com a elaboração de um recurso relacionado ao ensino-aprendizagem:

Há vários tipos de estudos que apresentam abordagem de controle qualitativo, e entre eles podemos citar a pesquisa para elaboração de material didático [...] Como o próprio nome indica, ela tem como objetivo expressamente claro produzir livro-texto, material audiovisual, equipamento específico, material de treinamento, enfim, 
qualquer produto essencial ao desenvolvimento do ensino-aprendizagem (RICHARDSON, 2009, p. 83).

A construção do recurso educacional objetivou facilitar o processo de aprendizagem de um aluno com TEA do segundo ano do curso técnico em agropecuária do ensino médio integrado do campus São Cristóvão do IFS, com foco na área da linguagem, e buscou integrar recursos e conteúdos. Para isso, foi utilizado o método do estudo de caso único, visto que o contato com a realidade e o contexto pesquisado permitiram "captar significados, analisar interações, compreender e interpretar linguagens, estudar representações, sem desvinculá-los do contexto e das circunstâncias especiais que se manifestam" (ANDRÉ, 2013, p. 97).

Portanto, o aluno com TEA foi a unidade de análise e para a elucidação do caso foram utilizados os instrumentos metodológicos da observação não participante e da entrevista semiestruturada. Tais instrumentos foram utilizados antes da criação do jogo (oferecendo dados para a elaboração) e, sobretudo, no processo de aplicação e análise na sala de aula.

No momento da aplicação, a observação demonstrou como os alunos interagiram com o jogo e de que forma o conteúdo era construído e discutido pelos alunos. Desta maneira, segundo Barros e Lehfeld (2007), na observação não participante, o pesquisador não se envolve diretamente nem faz interferência na situação em estudo. Já as entrevistas se constituíram fontes para a análise do jogo na percepção dos participantes. Lüdke (2011) atribui como maiores qualidades da entrevista a possibilidade de interação com os sujeitos e o acesso imediato às informações pretendidas.

A execução do jogo aconteceu sob a aquiescência e contribuição do professor de língua portuguesa do campus. Também houve a participação de uma integrante da equipe multidisciplinar Técnica em Assuntos Educacionais, além, é claro, da turma do segundo ano (com vinte e quatro alunos) de que o aluno do caso faz parte.

Objetivando uma melhor análise, a turma foi dividida em dois grandes grupos, nos quais o professor da turma recebeu um exemplar do jogo e ficou responsável pela aplicação em um grupo e a Técnica em Assuntos Educacionais aplicou o jogo com o outro grupo.

As entrevistas tiveram dois recortes. Primeiro, foi a percepção dos professores e alunos enquanto práticas educativas e inclusão e, depois, a experiência do jogo com o aluno do caso. Participaram das entrevistas cinco professores do aluno em diferentes áreas do conhecimento, o professor de Língua Portuguesa, a Técnica em Assuntos Educacionais e seis alunos (com idades entre 14 e 16 anos). O critério de inclusão dos alunos para participarem das entrevistas foi a manifestação da própria vontade bem como a permissão dos pais ou responsáveis através do termo de assentimento livre e esclarecido.

Os participantes foram identificados da seguinte forma: 
Tabela 1 - Participantes da pesquisa

\begin{tabular}{|l|l|c}
\hline Perfil & Sujeitos & Identificação \\
\hline \multirow{3}{*}{ Professores } & Professor de Produção Vegetal & P1 \\
& Professora de Artes & P2 \\
& Professora de Língua Portuguesa & P3 \\
& Professor de Apicultura e Produção Animal & P4 \\
& Professora de Inglês & P5 \\
\hline \multirow{3}{*}{ Aplicadores do Jogo } & Professor de Língua Portuguesa & P6 \\
& Técnica em Assuntos Educacionais & P7 \\
& Aluno A & P8 \\
& Aluna B & P9 \\
& Aluna C & P10 \\
\hline Alunos Participantes & Aluno D & P11 \\
& Aluno E & P12 \\
& Aluno do Caso & P13 \\
\hline
\end{tabular}

Fonte: Dados da pesquisa (2019)

Utilizamos como técnica a análise de conteúdo, obedecendo a algumas características metodológicas: objetividade, sistematização e inferência. Para Bardin (2010, p. 127) os dados devidamente tratados possibilitam ao pesquisador fazer "inferências e adiantar interpretações a propósito dos objetivos previstos, ou que digam respeito a outras descobertas inesperadas". Portanto, extraímos das entrevistas, bem como das observações, as respostas e ideias que melhor elucidaram o estudo, comparando os dados obtidos com os pressupostos teóricos.

\section{O jogo Imagem e Interação como estratégia inclusiva}

Como já falamos, a inclusão educacional não se efetiva com a entrada de alunos no sistema regular de ensino, mas depende do planejamento voltado para a aprendizagem de todos os alunos, incluindo, assim, a aprendizagem dos alunos com deficiências, seja de ordem física ou intelectual. A chegada de tais alunos na escola é somente o início; a inclusão, mesmo, acontece no próprio processo educacional, do qual faz parte o currículo, a convivência, as práticas pedagógicas e. enfim, o aprendizado.

Quando falamos em aprendizagem de um aluno com TEA no ensino médio, precisamos focar no seu perfil comunicacional, uma vez que a linguagem é um dos aspectos 
que apresenta maior deficiência nos casos que envolvem o TEA - o que não é diferente no estudo do caso em questão, em que a inserção ao meio social é limitada pela fragilidade comunicacional.

Portanto, promover possibilidades, criar estratégias para o aprimoramento da aprendizagem do aluno com TEA e outros alunos em situação de inclusão é pensar em práticas educativas que contemplem todos os alunos, ainda que o processo de aprendizagem individual seja distinto. Para Santos (2017), a inclusão é justamente ensinar pensando em ações para o desenvolvimento de todos.

Assim sendo, o jogo Imagem e Interação foi elaborado na perspectiva de analisar a participação do aluno com TEA, ao mesmo tempo em que se analisava a participação de todos. Na verdade, a própria base teórica do jogo compreende a aprendizagem voltada à cooperação do "outro" e da mediação na elaboração de conceitos e conhecimentos. Segundo Vygotsky (2008), o desenvolvimento do sujeito começa no intercâmbio social - o que acontece através da comunicação.

Os jogos educativos, como o jogo Imagem e Interação, contribuem significativamente para o desenvolvimento de atitudes sociais, uma vez que pressupõem relação social e interação, além de promoverem respeito mútuo, iniciativa, cooperação e principalmente o valor do grupo para a formação do pensamento. Estas características dos jogos educativos também estão presentes quando falamos em uma educação inclusiva. Desta maneira, o jogo em questão é um instrumento que possibilita uma prática educativa inclusiva. E nesta questão, a sala de aula é o ambiente onde os valores inclusivos estão imbrincados na interação e na aprendizagem de conteúdos.

É importante dizer isso porque quando se elabora um jogo educativo, além dos aspectos próprios do jogo como lazer, distração e prazer, não podemos perder de vista a intenção pedagógica. Em outras palavras, o que meus alunos aprenderão com tal prática? Portanto, podemos resumir prática pedagógica da seguinte forma:

A prática pedagógica é compreendida como uma prática social conduzida por objetivos, finalidades e conhecimentos. Considerando o contexto social, ela presume uma relação teoria-prática em que ambas se influenciam e podem gerar modificações uma na outra, havendo, assim, uma dependência mútua entre teoria e prática (BIGATE e LIMA, 2019, p. 05).

Prática pedagógica inclusiva nada mais é do que observar os critérios de objetivos, finalidades e conhecimentos; mas, agora, não para um público idealizado e excludente e, sim, reconhecendo e valorizando as diferenças. Em suma, os recursos educativos precisam propiciar aprendizagem e construção de conhecimento para todos os sujeitos na sala de aula. Teles (2017) entende que "a escola é um dos principais espaços de convivência da sociedade e, considerando que esta possui um método, um objetivo e uma rotina de funcionamento, precisa estar preparada para lidar com as diferenças"' (TELES, 2017, p. 61). 
O jogo Imagem e Interação, então, vai para a sala de aula objetivando o aprendizado não somente do aluno do caso, mas, sim, na partilha em grupo. Ele contempla a leitura visual a partir da própria vivência dos alunos. E o intuito é promover a interação e desenvolvimento da habilidade social entre os participantes e, através das interpretações variadas sobre uma mesma imagem, perceber que o signo imagético, que compõe ojogo, está imbrincado de intencionalidades. O que se espera dos participantes é que consigam estabelecer nexos coerentes entre as imagens, ou seja, consigam perceber a intertextualidade nos signos não verbais.

A intervenção pedagógica a partir do jogo permite a participação dos alunos em uma situação interativa e o trabalho de forma cooperativa. Desta forma, o jogo e o aspecto social se fundem, a fim de trazer ambientes conflitantes, os quais, bem mediados, possibilitam o desenvolvimento cognitivo, afetivo e relacional/social do aluno.

Ao adotar jogos como mais um recurso pedagógico, o professor possibilita aos alunos se apropriar dos conhecimentos de maneira mais prazerosa. Desse recurso prático integrado "surge o aluno ativo e participativo em um ambiente total, e aparecem o apoio e a confiança que lhes permite desenvolver qualquer habilidade necessária para a comunicação dentro do jogo" (TEZANI, 2006, p. 02).

Enquanto lógica metodológica, o jogo encontra suporte na teoria histórico-cultural de Vygotsky (2008), pela qual a relação entre o processo de desenvolvimento e a capacidade de aprender e de melhor se expressar do aluno com TEA acontece pela troca de experiência entre ele e seus pares, através da mediação do recurso pedagógico e tendo a linguagem como articuladora do processo de formação e aprimoramento de conceitos. Enquanto conteúdo, o jogo circunda a constituição da linguagem, sua relação com o pensamento e, mais precisamente, sobre a intertextualidade imagética.

Em Santos e Ferreira (2017), a linguagem é concebida enquanto expressão do pensamento, como instrumento de comunicação e como interação. Entendemos a importância e uso das três concepções indicadas pelos autores, mas é na percepção da linguagem como interação que temos interesse. Nesta concepção, nosso olhar volta-se para o processo de interação entre os sujeitos - os quais desenvolvem práticas através do uso social da linguagem. Os sujeitos são, assim, agentes sociais através do recurso do diálogo.

(...) O interlocutor deixa de ser passivo, de absorver, decodificar e repassar as informações, passando a exercer o papel de sujeito ativo, fazendo as inferências pertinentes, pautado no meio social para produção do enunciado. O sujeito, por meio da linguagem, interage de forma significativa com o meio e com o outro, promovendo práticas dialógicas no processo de apreensão e construção do conhecimento (SANTOS e FERREIRA, 2017, p. 334).

Em relação ao recurso das imagens (que é um tipo de linguagem), entendemos que a análise do texto visual carrega uma rede de significações e possibilidades interpretativas, o que contribui para o processo de aprendizagem e competência comunicacional 
do aluno do caso, bem como de todos os alunos. Ao associar imagens e discurso há a intertextualidade imagética e tal associação ou leitura visual pressupõe coerência, referenciação e inferências oriundas das experiências e leitura de mundo dos alunos. O jogo proporciona aos alunos (sobretudo o aluno com TEA) trazer para a fala as próprias representações mentais e significados atribuídos às imagens.

Aprender a direcionar os próprios processos mentais com ajuda de palavras ou signos é uma parte integrante do processo da formação de conceitos. A capacidade para regular as próprias ações fazendo uso de meios auxiliares atinge o seu pleno desenvolvimento somente na adolescência (VYGOTSKY, 2008, p. 74).

O jogo Imagem e Interação traz a leitura relacionada de imagens como um recurso a ser utilizado no campo educacional, sobretudo numa perspectiva sociointeracionista e inclusiva, pois não somente estimula comunicação e mediação, mas também valoriza a realidade cultural dos alunos, a construção de diálogos, possibilita ao sujeito novas leituras, traduzindo assim o caráter dinâmico da prática pedagógica na sala de aula.

\section{Manual do jogo}

Imagem e Interação é um jogo de cartas imagéticas com cunho didático-pedagógico e elaborado para o desenvolvimento da área de linguagem e comunicação, a partir da interpretação das imagens numa relação intertextual entre elas.

Apresentação do jogo:

a. Áreas de desenvolvimento: linguagem, interpretação, concentração, atenção, socialização, intertextualidade.

b. Materiais: Tabuleiro de madeira, três dados, 120 cartas imagéticas plastificadas, placa de pontuação, marcador e manual.

c. Público alvo: adolescentes do ensino fundamental II ou ensino médio.

d. Quantidade de participantes: 3 jogadores individuais ou 3 grupos com, preferencialmente, 5 participantes, no máximo, em cada grupo.

e. O mediador: é um participante com o perfil de "julgador" e que conhece bem o jogo, as regras, e tem conhecimento prévio das cartas.

Como jogar:

1. O jogo possui 06 (seis) blocos temáticos e em cada bloco há 20 (vinte) cartas referentes aos temas: sentimentos, lugares, arte e literatura, fatos históricos, meio ambiente e temas variados. 


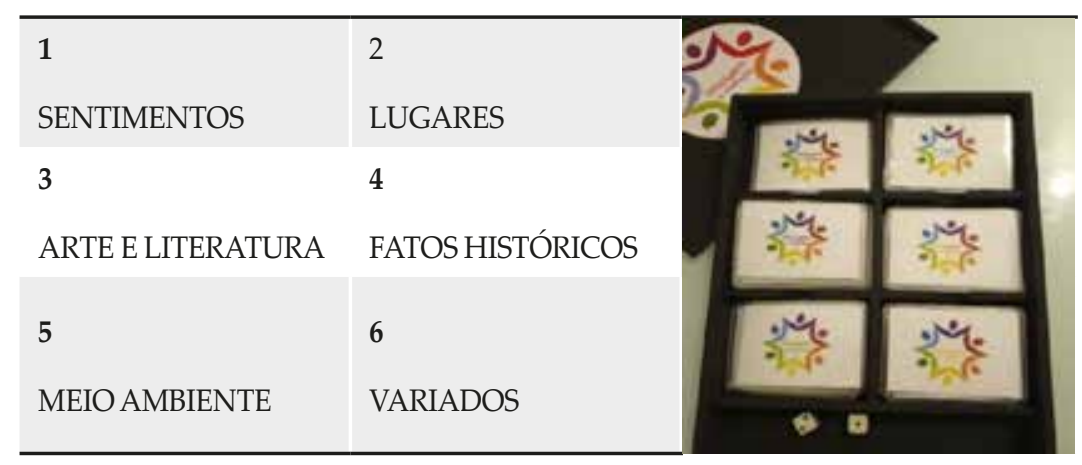

2. Cada bloco temático possui um número, que corresponde à numeração do dado (1 a 6).

3. Cada participante deverá jogar o dado e pegar uma carta no bloco correspondente.

4. A cada rodada um participante é chamado de Argumentador da Vez.

5. O Argumentador da Vez joga o dado e tira a sua carta. E espera que os demais participantes façam o mesmo.

6. Os participantes ao tirarem a carta devem colocá-la na mesa e falar algo sobre ela (uma palavra-chave, uma experiência, ou algo que simbolize aquela carta para ele).

7. O Argumentador da Vez deve ser o último a colocar a carta na mesa e tenta estabelecer uma relação entre as cartas dos outros participantes com a sua (a relação entre as cartas diz respeito aos aspectos de coerência, a intencionalidade e possibilidade de intertextualidade entre elas).

8. O Argumentador da Vez deverá através do discurso convencer os demais participantes da relação estabelecida entre as cartas.

9. Sistema de pontuação: Quem julga a relação interpretativa feita pelo Argumentador da Vez são os próprios participantes, contudo, há a participação do mediador - que pode concordar ou discordar, com a devida justificativa.

Pontuação:

- 0 pontos - Quando não for possível estabelecer nenhuma relação entre as imagens.

- 1 ponto - Quando o Argumentador da Vez conseguir fazer relação da sua carta com 1(uma) carta de um dos participantes. 
- 2 pontos -Quando o Argumentador da Vez conseguir fazer relação da sua carta com as 2 (duas) cartas dos participantes, separadamente.

- 3 pontos-Quando o Argumentador da Vez conseguir estabelecer uma relação entre as 3 (três) cartas juntamente.

- Observação: Os outros participantes/grupos recebem 1 ponto ao colocar a carta na mesa e falar algo que represente a referida carta.

10. Fim de jogo. Os pontos serão marcados na placa de pontos e o jogo termina quando um dos participantes finalizar 10 (dez) pontos na placa de pontos, ou quando o jogo estiver sendo executado por um período aproximado de 50 minutos.

\section{Análise da prática educativa e inclusiva}

Como esclarecido na metodologia, primeiramente versaremos sobre as práticas pedagógicas e o processo de inclusão na visão dos professores participantes da pesquisa. Depois, sim, focaremos no jogo Imagem e Interação na sala de aula e em seus aspectos inclusivos.

Antes de focar na prática pedagógica, uma pergunta foi basilar para entender a realidade estudada. Assim, a pergunta "como foi ter um aluno com TEA na sala de aula?" ensejou um estudo rico sobre como o desconhecimento talvez seja o maior empecilho para a promoção de uma educação mais inclusiva.

Nas falas de P1, P2, P3, P4 e P5 registram-se palavras como pânico, medo, sentimento de incompetência, insegurança, diferente, preocupação, surpresa, desafio, dentre outras com a mesma carga semântica. Mas em todas as falas ficou perceptível a ideia da estranheza que o novo causa, o que acontece porque normalmente tomamos por base outro referencial de aluno, construído socialmente. "Foi uma novidade, uma coisa diferente para mim. Você ter um aluno que não participa igual aos outros. Mas foi um aprendizado. [...] No início os próprios colegas o tratavam assim diferente, não o tratavam muito bem. Até que eles entenderam que ele era diferente no que diz respeito ao comportamento. Eles brincavam muito, falavam umas palavras que incomodava. Aí eu comecei a interferir, a exigir respeito" (P1).

Essa fala é parte de um script que registra um estranhamento permanente, pois dá forma à percepção de que os territórios escolares têm sido lentamente ocupados também por pessoas que, a priori, são entendidas como se fossem sujeitos que não deveriam ou poderiam estar ali (FREITAS, 2013, p. 17).

Portanto, o primeiro passo é pensar a aprendizagem do aluno com TEA não em comparação ao outro, pois senão o estaríamos reduzindo às suas dificuldades. Quando 
percebermos as suas peculiaridades fica mais fácil não somente ter uma atitude inclusiva com ele, e sim, uma sala de aula inclusiva. A escola é uma construção histórica em que ainda prevalecem princípios homogeneizantes. Quando nos deparamos com o diferente, com o novo, somos impelidos a reações de medo e repulsa.

"Foi um desafio, a minha reação inicial foi um choque. Como a gente ia lidar, se normalmente a sala de aula já é um ambiente heterogêneo e a gente tenta atender a todos. $E$, neste caso, como atender um aluno autista, como se comportar? [...] Houve uma tentativa de inclusão, mas o difícil foi não ter uma preparação antes" (P5). É claro que a fala de P5 traduz uma realidade da inclusão nas escolas: a comunidade escolar, principalmente os professores, não foi capacitada para trabalhar com alunos com deficiências ou com transtornos globais do desenvolvimento. No entanto, a resposta para o questionamento de P5 já está na própria fala, pois quando declara que a sala já é, por si só, um ambiente heterogêneo, podemos entender a sala de aula como o ambiente da diversidade.

Na fala dos alunos P8, P9 e P10 também houve estranhamento quando o aluno chegou na escola, pois ele mostrava um comportamento alheio ao que os colegas falavam, não agia conforme o contexto da sala estava condicionado: “Diferente até na parte de lidar com ele. Desde o primeiro dia de aula todo mundo deu risada (assim brincando), porque ele perguntava, perguntava e perguntava ao professor. Aí nós falamos: - Nossa, ele é inteligente! Mas o difícil é a forma que ele age de vez em quando" (P8). Desta maneira, um tabu a ser repensado quando falamos em inclusão é o de associar o assunto a questões de inteligência e capacidade de aprendizagem. Ficar surpreso com a inteligência do aluno é o mesmo que denunciar o pensamento de desvalorização que alimentamos acerca das potencialidades da pessoa com deficiência.

Pensar o sentido inclusivo em formação de professores é visualizar o ser humano nas suas possibilidades, nos seus desejos, nas suas buscas, percebendo a deficiência como uma condição humana, que não define o ser na deficiência, mas define a especificidade da mediação fundante para eliminar barreiras (LIMA, 2012, p. 84).

Esta percepção faz toda diferença na condução dos colegas e dos professores, pois entender a especificidade que o aluno traz é o que de fato cria as possibilidades de aprendizagem e da salutar inclusão educacional. $O$ foco na aprendizagem parece ser o melhor caminho para concretizar a inclusão, que não é um ato em si mesma, mas um processo, onde as práticas educativas reverberam o quanto nosso pensamento é de inclusão ou de segregação educacional.

No grupo de perguntas sobre as práticas e estratégias educativas em sala de aula, grande parte dos professores relatou que não pensa nas aulas a partir das necessidades dos alunos e que normalmente como as turmas são heterogêneas percebe que alguns alunos se desenvolvem mais que outros, inclusive o aluno com TEA. Para eles, o aluno deve ser tratado como os demais: "Olhe, pra ser sincero, não faço diferente nas minhas 
aulas. A gente dá aquela aula (não vou dizer uniformizada), mas a gente não fica pensando 'ah, tenho que ter cuidado com isso ou aquilo'. Entro na sala e dou aquela aula como não tivesse aluno com problema nenhum, pra mim é como se ele fosse igual a todo mundo, (risos) não sei se estou certo ou errado" (P6).

Opiniões como esta têm, pelo menos, duas perspectivas de análise. A primeira, positiva, diz respeito à inclusão com os outros colegas, ou seja, o simples fato de perceber o aluno como integrante ativo da sala de aula já é uma postura inclusiva. Conforme Silva (2014), a inclusão consiste em reunir os alunos de maneira geral para que eles aprendam juntos.

No entanto, há outra situação nesta mesma fala de P6, que é fugir da ideia da equidade, uma vez que as condições de aprendizagem não são as mesmas para todos os alunos, e isso é também uma responsabilidade da escola, ou seja, pensar na aprendizagem de todos os alunos, inclusive daqueles com deficiência. Em outras palavras, atenuar a deficiência não é o melhor caminho.

Ao tentarmos atenuar ou negar as deficiências, é como se disséssemos: “Aceitamos você sem olhar para sua deficiência". O que poderá trazer sérias implicações para o desenvolvimento e a aprendizagem do aluno com deficiência ou que esteja em outra condição (SILVA, 2014, p. 30).

Podemos concluir que pensar de maneira inclusiva não quer dizer ignorar as particularidades e necessidades de aprendizagem do aluno. Esta afirmação é a base para promover práticas pedagógicas inclusivas. Quando o jogo Imagem e Interação foi elaborado, foi considerada a observação do contexto cultural que permeava não somente o aluno com TEA, mas toda a turma. Na sala de aula, o aluno com TEA demonstrava interesse em aprender sozinho, com muita dificuldade em dividir sua opinião com os colegas. Era como só existisse ele e o professor na sala de aula: os comentários, brincadeiras e conversa dos seus pares não o abalavam, nem o faziam olhar para os lados. Ele estava sempre olhando para o professor ou para baixo.

A ideia de uma prática educativa inclusiva deveria, então, promover melhores formas de aprendizagem para todos. O jogo precisaria trazer condições para o aluno com TEA aprender com a turma, e a turma também aprender com ele, pois não há mais espaço para modelos de práticas que promovam a segregação entre os alunos. Para P7, o jogo permitiu "uma experiência de ensino-aprendizagem de forma lúdica. Os alunos conseguiram juntos explorar suas capacidades linguísticas sem se darem conta que estavam exercitando, motivados pela competitividade e interação que o jogo produz".

A experiência de jogar junto demonstrou que às vezes o que se precisa é proporcionar o ambiente inclusivo. Se limitássemos às características do TEA e do que o aluno demonstrava na sala de aula, possivelmente não pensaríamos na prática em que o foco foi a aprendizagem a partir do social, a partir da interação. 
Para Vygotsky (2007; 2008), a interação propicia a construção da aprendizagem e é aspecto central para o desenvolvimento da pessoa. A teoria histórico-cultural credita às interações e experiências sociais a origem das funções psicológicas superiores, como memória, antecipações e inferências. E a linguagem se constitui como mediadora da aprendizagem.

Tanto P13 (aluno com TEA) como os demais colegas mencionaram a participação no jogo através do diálogo, do discurso e da ação interativa entre eles: "A participação de P13 foi muito boa, pois ele conseguiu dialogar com a gente e discutir os temas, e acabou ajudando a equipe a marcar ponto" (P11). A própria fala de P13 demonstra a sua participação: "a gente vê o que a imagem tá mostrando e tenta assimilar com as outras através de palavras e frases" (P13). O importante na fala de P13 é exatamente perceber a referenciação à participação do grupo e ao uso da linguagem para a construção de conceitos.

Quando questionado a respeito do recurso do jogo em sala de aula, P13 disse que "foi diferente, pois as vezes tem jogos na sala [...] mas não são jogos assim compartilháveis". A palavra "compartilháveis" dita por P13 tem uma conotação de cooperação, de um conteúdo e discurso que vai sendo construído pela participação do outro. Isso para um aluno com TEA é de suma importância, visto que perceber esse outro é normalmente um desafio para a sua efetiva comunicação. "As pessoas com Transtorno do Espectro Autista apresentam dificuldades relacionadas a essas capacidades requeridas pelo jogo humano" (MATTOS e SOUZA, 2017, p. 24). Portanto, ao jogar, não somente os alunos estavam discutindo a intertextualidade imagética, na verdade, estavam construindo ou participando do jogo humano, expresso na comunicação recíproca, na atenção e nos próprios sinais emitidos pelo corpo, como vibrar pelos pontos.

Um momento importante da observação foi presenciar a comemoração de P13 com os integrantes da sua equipe, evidenciando como o jogo é uma prática propícia quando se objetiva a construção coletiva. Quando solicitados a resumir o jogo em uma palavra, obtivemos as seguintes contribuições: interessante, amizade, interpretação, imagem, ajuda e pensamento. "No meu grupo pode ser a amizade, porque a gente estava competindo um com outro, mas quando acabou, quando completamos os pontos todo mundo ficou feliz pelo outro, deu parabéns. Isso aí eu achei bem legal, o jeito que a gente estava competindo" (P9).

Para um dos aplicadores , a experiência com o jogo foi prazerosa, uma vez que, "uma aula lúdica é sempre bem-vinda. Um jogo é sempre um atrativo, porque além de quebrar a monotonia de uma aula convencional, permite aos alunos exercitarem suas habilidades com mais prazer" (P6). A palavra prazer e termos similares aparecem também nas falas dos participantes P7, P8, P9 e P12, o que mostra que o jogo facilmente suscita a ideia de algo prazeroso, por isso mesmo não deve ser um recurso voltado tão somente às séries iniciais, mesmo porque todo ser humano é movido, de certa forma, pelo princípio do prazer. 
É importante perceber que não é porque o jogo é algo prazeroso que não é um desafio jogá-lo, principalmente quando se trata de um jogo educativo, que tem fins pedagógicos.

\begin{abstract}
A habilidade rapidamente recorre à inteligência para se transformar em engenhosidade. Trata-se de explorar da melhor forma possível, ao mesmo tempo, a situação produzida pelo desenrolamento do jogo e as possibilidades oferecidas pelo material e as convenções (VIAL, 2015, p. 115, grifo nosso).
\end{abstract}

Portanto, o recurso pedagógico deve atender a um objetivo e oferecer possibilidades de aprendizagem, neste caso, uma aprendizagem sociointeracionista e inclusiva, onde são ressaltadas as potencialidades dos participantes em trazer para o discurso suas interpretações imagéticas a partir da própria visão de mundo. Vale dizer que por recurso pedagógico entendemos os "instrumentos utilizados para o ensino e a aprendizagem dos alunos" (SHIMAZAKI e PACHECO, 2012, p. 131).

E quando falamos de recurso pedagógico inclusivo, tem alguma diferença? Grosso modo, entendemos que não, pois para o aluno em situação de inclusão também vale a centralidade em sua aprendizagem. No jogo em questão, por exemplo, o fator inclusivo estava no princípio que norteava o jogo, nas regras que faziam o jogo e não no recurso em si.

Isso mostra que para um material pedagógico ser inclusivo precisa atender as necessidades dos alunos em seu contexto histórico e cultural. Desta forma, se o aluno com TEA fosse manipular o jogo Imagem e Interação sozinho numa sala, ele poderia até atingir os aspectos cognitivos da intertextualidade entre as imagens, contudo, não conseguiria atender o aspecto inclusivo e a dimensão relacional do jogo.

Ainda sobre o jogo ser uma prática que cria possibilidade de aprendizagem, P7 declara que "foi gratificante ver a adesão de todos os alunos e o que o jogo proporcionou. Mostra que o professor e a escola precisam pensar em abordagens mais atrativas e estimulantes para os jovens". Na fala de P10 o atrativo do jogo estava na "possibilidade de ajuda que um podia dar para o outro na relação das imagens". E para P6, em relação a participação do aluno com TEA no jogo foi "muito boa, ele não só contribuiu, como fez ótimas análises das imagens. Em alguns momentos me solicitava opiniões".

Todas as falas transcritas demonstram como a mediação é basilar para o desenvolvimento do sujeito, de forma que o auxílio ou ajuda do outro é uma instância para o sujeito alcançar outros níveis de aprendizagem, o que Vygotsky (2008) chama de Zona de Desenvolvimento Proximal. E a mediação pedagógica para Shimazaki e Pacheco (2012),

é essencial na formação dos conceitos científicos e no desenvolvimento das funções psicológicas superiores. Sua ação precisa ser direcionada para a organização de conteúdos que possibilitem ao aluno exercitar seus processos mentais, proporcionando diferentes níveis de desenvolvimento (SHIMAZAKI; PACHECO, 2012, p. 79). 
Por isso mesmo, o jogo Imagem e Interação, como um recurso de mediação pedagógica, integrou os alunos não pelo quanto que sabiam dos conteúdos expressos nas cartas, mas pelo simples fato de focar nas possibilidades que todos tinham. Uma educação inclusiva, portanto, se faz quando a intenção na sala de aula é oferecer recursos que possibilitem a integração e cooperação de todos os perfis de alunos, respeitando, contudo, o nível e processo de desenvolvimento individual.

\section{Considerações finais}

O estudo analisou a educação inclusiva a partir do recurso pedagógico do jogo Imagem e Interação, intencionalmente elaborado para ser jogado em sala de aula e com a participação de todos os alunos. Perceber como os alunos interagiram para a construção do pensamento coletivo mostrou como o contexto histórico e cultural da sala de aula é representativo para os estudos voltados à inclusão educacional.

O fato de o aluno em situação de inclusão passar a frequentar uma escola do ensino regular é uma conquista; no entanto, não garante a efetiva inclusão. Precisamos mudar o nosso olhar para a realidade da escola na contemporaneidade. Se antes a escola tinha um tipo de aluno como referência, hoje há heterogeneidade e, na diversidade, se encontram também os alunos com deficiência de diferentes ordens.

Deve-se, então, focar a inclusão nas práticas educativas das escolas. No IFS, local desta pesquisa, a inclusão de um aluno com TEA foi uma novidade - como ainda o é em muitas escolas. Por isso, o sentimento de medo e incapacidade só demonstra o estranhamento com o novo. Isso é normal, desde que não se configure em empecilho à promoção da aprendizagem do aluno com TEA, assim como para outros alunos em situação de inclusão.

O jogo Imagem e Interação nasceu da ideia de oportunizar e analisar a aprendizagem do aluno com TEA de maneira lúdica e principalmente cooperativa, ressaltando a importante função da linguagem para a organização do pensamento, como elemento primordial da comunicação. E, por conseguinte, um elemento capaz de ressignificar a inclusão - que passa pela interação como o outro.

Assim, quando se pensa em um recurso para a prática educativa na sala de aula, é importante que previamente se verifiquem as possibilidades do referido recurso e o objetivo que se pretende com o material a se usar. Neste estudo, o recurso do jogo Imagem e Interação tinha o intuito de promover, através das relações entre as imagens, um aprendizado construído de maneira cooperativa e dialógica, de forma que evidenciasse não as dificuldades ou características individuais dos alunos (principalmente o aluno com TEA), mas que o foco estivesse na percepção de que o conhecimento pode ser melhor aproveitado ou apreendido quando se valoriza a fala do outro. 
Em suma, não se faz inclusão educacional sem o contato direto com os alunose sem a aceitação da diversidade na sala de aula. Esta, então, através das diferentes oportunidades, métodos, recursos e estratégias demonstra ser um ambiente, por natureza, propício a desenvolver a prática inclusiva.

Recebido em: 13/01/2020 e Aprovado em: 10/04/2020

\section{Referências}

ANDRÉ, M. E. D. A. O que é um estudo de caso qualitativo em educação? Revista da FAEEBA Educação e Contemporaneidade. Salvador, v. 22, n.40, p. 95 -103, 2013.

BARDIN, Laurence. Análise de conteúdo. 4. ed. Lisboa: Loyola. 2010.

BARROS, Aidil J. da S.; LEHFELD, Neide Aparecida de S. Fundamentos de metodologia científica. 3. ed. São Paulo: Pearson Prentice Hall, 2007.

BIGATE, Thaís Ferreira; LIMA, Neuza Rejane Wille. Práticas pedagógicas no processo de reabilitação de alunos com surdocegueira. Revista Educação Especial, Santa Maria, p. e66/ 1-23, jun. 2019.

FREITAS, Marcos Cezar de. O aluno incluído na educação básica: avaliação e permanência. $1^{1}$ ed. - São Paulo: Cortez, 2013.

HOFFMANN, Jussara. O jogo do contrário em avaliação. 10 ed. - Porto Alegre: Mediação, 2018.

LIMA, Iara Maria Campelo. Tecendo saberes, dizeres, fazeres em formação contínua de professores: uma perspectiva de educação inclusiva. São Cristóvão: Editora UFS, 2012.

LÜDKE, M.; ANDRÉ, M. E. D. A. Pesquisa em educação: abordagens qualitativas. São Paulo: E.P.U., 2011.

MATTOS, Michele M. de M; SOUZA, Rita de C. S. Inclusão na educação infantil: o que diz a literatura sobre o brincar da criança com transtorno do espectro autista? In: Rita de Cácia Santos Souza (org.). Tons de Azul: múltiplos olhares sobre o Transtorno do Espectro Autista (TEA). Aracaju: Criação, 2017, p. 23-40.

MEC. Cresce a cada ano o número de crianças atendidas pela educação especial no Brasil. [online], 21 de março de 2019.

RICHARDSON, Roberto Jarry. Pesquisa social: métodos e técnicas / Roberto Jarry Richardson; colaboradores José Augusto de Souza Peres (et al.) - 3. Ed. - São Paulo: Atlas, 2009.

RODRIGUES, Jessika Castro. Caminhos de formação em música de estudantes com transtorno do espectro do autismo em uma escola técnica em música. Dissertação de Mestrado) - Universidade Federal do Pará, Instituto de Ciências da Arte, Belém, 2014.

SANTOS, D. O. B.; FERREIRA, A. A. C. Concepção de leitura e de linguagem: implicações na formação e no desenvolvimento do leitor proficiente. Revista Humanidades e Inovação, Palmas, v. 4, nº 2, 331-343, junho, 2017. 
SANTOS, Fabiana C. Autismo e educação: uma reflexão acerca da escola comum inclusiva. In: Rita de Cácia Santos Souza (org.). Tons de Azul: múltiplos olhares sobre o Transtorno do Espectro Autista (TEA). Aracaju: Criação, 2017, p. 127-152.

SCHWARTZMAN, J. S.; ARAUJO, C. A. Transtornos do espectro do autismo - TEA. São Paulo: Memnon, 2011.

SHIMAZAKI, Elza M.; PACHECO, Edilson R. Deficiência e inclusão escolar. Maringá: Eduem, 2012.

SILVA, Luzia Guacira dos Santos. Educação inclusiva: prática pedagógica para uma escola sem exclusões. 1ํe․ - São Paulo: Paulinas, 2014.

TELES, Perolina Souza. A aprendizagem como instrumento de inclusão social. In: Rita de Cácia Santos Souza (org.). Perspectivas sobre educação inclusiva. Aracaju: Criação, 2017.

TEZANI. T. C. R. O jogo e os processos de aprendizagem e desenvolvimento: aspectos cognitivos e afetivos. Educação em Revista, Marília, v. 7, nº 1/2, 1-16, maio, 2006.

VIAL, Jean. Jogo e educação: as ludotecas. Petrópolis, RJ: Vozes, 2015.

VYGOTSKY, Lev Semenovich, 1896 - 1934. Pensamento e linguagem. Tradução Jefferson Luiz Camargo,

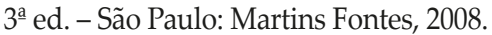

VYGOTSKY, Lev Semenovich. A formação social da mente: o desenvolvimento dos processos psicológicos superiores. $7^{\mathrm{a}}$ ed. - São Paulo: Martins Fontes, 2007. 